\title{
Globalización y migraciones Una mirada desde Europa solidaria con el Sur
}

JosÉ ANTONIO ZAMORA

Para acercarse con un mínimo de garantías de comprensión al fenómeno migratorio, es necesario adoptar una perspectiva que supere los límites de lo meramente local. Atender a las desigualdades que desgarran nuestro mundo, a las relaciones de las antiguas metrópolis con sus ex-colonias, al crecimiento de los intercambios comerciales internacionales, a la deuda externa que ahoga a los países empobrecidos, al deterioro medioambiental que golpea a las poblaciones más desprotegidas de esos países, al impacto masivo de la cultura del entretenimiento a escala planetaria y al abaratamiento y expansión de los medios de transporte, a la evolución de los mercados de trabajo de los países desarrollados; en suma, atender a todos estos factores resulta imprescindible cuando queremos analizar los movimientos migratorios.

\section{Sistema-mundo capitalista y flujos migratorios}

En realidad, esto no es una novedad. Como resaltan los representantes de la teoría del sistema-mundo capitalista, las migraciones forman un subsistema del mercado mundial. Dada la naturaleza expansiva del proceso de acumulación capitalista y del deseo de reducir los costes del factor trabajo, la evolución del sistema económico siempre ha ido acompañada de una demanda de fuerza de trabajo. Y cuando ésta

Globalización y migraciones. Una mirada desde Europa solidaria con el Sur 
no ha estado suficientemente disponible o no lo ha estado en las condiciones de flexibilidad, bajo coste, etc., deseadas, se ha buscado salida en los trabajadores más o menos libremente captados en el exterior.

De hecho, la expansión del capitalismo ha estado unida de modo inseparable a la renovación permanente de los potenciales migratorios a través de la incorporación a la división internacional del trabajo de nuevas zonas convertidas así en periferias del sistema. Se ha tratado por regla general de una dinámica que une la desventajosa integración de esas periferias en el sistema mundial, por un lado, y la desintegración de las formas tradicionales de reproducción de la vida y la generación de potenciales migratorios, por otro.

Pensemos, por ejemplo, en el desplazamiento de población europea que acompañó los diversos procesos de colonización. Se calcula que hasta 1850 fueron trasladados unos 15 millones de esclavos africanos al continente americano. Tampoco dudaron las potencias coloniales en trasladar trabajadores de las colonias que poseían en un continente a las que poseían en otro, la mayoría de las veces obligándolos a trabajar en condiciones de casi esclavitud. A partir de 1850 se fue constituyendo un mercado internacional de mano de obra sin excesivas trabas como elemento fundamental del mercado capitalista mundial. Se estima que entre 1846 y 1932 emigraron unos 50,5 millones de europeos, principalmente al continente americano. El hecho de que esta emigración "voluntaria", y la menos voluntaria de mano de obra trasvasada entre las colonias, pudiera desarrollarse sin trabas responde sin duda a que los países emisores u organizadores eran los que detentaban el poder mundial.

También el proceso de crecimiento económico de la postguerra provocó un auge de los flujos migratorios hacia los países del centro de importancia indudable. Nadie duda hoy de la significativa aportación de los inmigrantes a ese crecimiento y al aumento del bienestar en dichos países. Trabajadores de la Europa periférica, italianos y españoles ( 2 millones), yugoslavos (1,5 millones), turcos ( 1 millón), griegos (500.000) y finlandeses (400.000), sin olvidar los trabajadores procedentes de las ex-colonias que llegaron a sus ex-metrópolis $(1,5$ millones de la Commonwealth al Reino Unido; 1 millón de magrebíes a Francia, 300.000 indonesios a Holanda), constituyeron un aporte de 
fuerza de trabajo que no sólo venía a cubrir la demanda dependiente del fuerte crecimiento, sino que también se usó para contrarrestar las exigencias de los trabajadores autóctonos y controlar la inflación. EE.UU., Canadá y Australia también experimentaron en la postguerra un crecimiento en la intensidad de la inmigración europea primero y asiática y latinoamericana después.

\section{La crisis del modelo económico de postguerra y la ofensiva neoliberal: liberalización y "cierre de puertas" a la inmigración}

En la década de los setenta del siglo XX el modelo de acumulación de la postguerra basado en la organización "fordista" de la producción, en la regulación de la economía por medio de la intervención del Estado (keynesianismo) y en los pactos sociales entre las organizaciones de los trabajadores y de los empresarios, modelo que permite a los países más desarrollados la creación del Estado del Bienestar, sufre una crisis profunda cuyos signos económicos más importante son la tendencia decreciente de los incrementos de la productividad y la caída de los beneficios. Dicha caída de los beneficios del capital productivo generó a su vez una sobreacumulación de capitales y un exceso de los mismos en los mercados financieros.

Pero una vez que el así llamado modelo "fordista" de las grandes unidades de producción, basadas en el trabajo en cadena y la fabricación de bienes de consumo baratos para las masas trabajadoras, toca techo, el sistema económico empieza a olvidarse del objetivo del pleno empleo, produciéndose una reorientación de todo el sistema de producción y distribución. El proceso de internacionalización de los intercambios y la producción, acompañado y propiciado por la liberalización de los mercados financieros, desplaza del centro de interés de las grandes empresas multinacionales a las amplias capas sociales de los mercados nacionales, colocando en su lugar a las clases con capacidad adquisitiva en todo el mundo.

Frente al pleno empleo, se opta por propiciar empleos cualificados y soportar una fuerza de trabajo excedentaria y excluida: el paro estructural; frente a una producción orientada a la totalidad de la población, se opta por otra orientada a mercados restringidos y de consumo selecto con gran poder adquisitivo. De ahí la creciente resistencia de los grandes consorcios, propiciada y facilitada por la deslocalización 
del capital, a seguir sufragando con sus impuestos las políticas redistributivas y sociales destinadas a los colectivos más desfavorecidos de los mercados nacionales. El círculo vicioso de inflación y paro hace su aparición y empuja a los Estados a un endeudamiento que acaba volviéndose insoportable.

Como respuesta a esta triple crisis productiva, financiera y fiscal se acaba imponiendo la "solución" neoliberal. Se lleva a cabo una reestructuración industrial con la incorporación de las nuevas tecnologías y una profundización de la transnacionalización de la producción. El comercio internacional sufre un proceso de liberalización asimétrica y el sector que lidera el control de la economía, las multinacionales, acentúan y profundizan las tendencias deslocalizadoras. La crisis financiera se afronta por medio de la exportación de capitales a los países en desarrollo (origen de la deuda externa) y una completa liberalización de los mercados financieros. En las economías nacionales se opta por la privatización y la reducción de la intervención del Estado en la economía, por poner freno o recortar las prestaciones del Estado del Bienestar y por poner como meta prioritaria de la política económica el control de la inflación, la limitación del gasto público, el equilibrio presupuestario, el déficit cero, etc. Un elemento clave de esa política es la desregulación y flexibilización del mercado de trabajo, con el consiguiente debilitamiento de las organizaciones sindicales y de su capacidad de negociación frente al capital.

La crisis económica de los años setenta trae consigo el final de una etapa de "puertas abiertas" y de fomento de la inmigración en los países industrializados de Europa y el comienzo de las restricciones y de la incentivación del retorno, lo que coincide con la aparición en la escena pública del "problema de la inmigración". Tras el fracaso de esas políticas, a partir de comienzos de los noventa, se va a levantar un "muro" legal y administrativo para restringir radicalmente las afluencias migratorias. Europa se presenta ante el mundo como una "fortaleza". Dicha política de "puertas cerradas" ha reducido en parte el número de entradas de inmigrantes, pero sobre todo ha modificado el tipo de flujos hacia la clandestinidad y la reagrupación familiar. Por otro lado, la estabilización de los flujos migratorios intracomunitarios y el crecimiento de los extracomunitarios ha producido cambios innegables en la fisionomía de la inmigración, en la que ya no predominan, como en los años 50 y 60 , los europeos del sur, sino cada vez 
más las personas provenientes de los países empobrecidos del Tercer Mundo.

\section{Globalización: lo que promete y lo produce}

En este contexto y en relación con el colapso del bloque soviético tras la caída del muro de Berlín comienza a extenderse el uso del término globalización. En la década de los noventa esta palabra se ha convertido en un concepto de moda con infinidad de matices cambiantes según el contexto en que se emplee. No sólo en las ciencias sociales se recurre a ella en cuanto categoría de primer rango para el diagnóstico del tiempo presente. También en la conciencia cotidiana, dominada por los modelos de interpretación de la coyuntura histórica que suministran los mass media, se va imponiendo la significación sobre todo económica de la globalización como característica fundamental de la época que nos ha tocado vivir.

No existe discurso político o intelectual en el momento presente que no termine refiriéndose de un modo u otro al fenómeno de la globalización: internacionalización de los mercados financieros, deslocalización de empresas y sociedades, libre circulación de mercancías, mundialización de la información y colonización cultural, etc.

Sumamente llamativo es el carácter pseudonatural que se le atribuye en el discurso público, como si se tratara de un fenómeno que "se" ha producido de manera casi inevitable, impuesto por la evolución tecnológica o por las "necesidades" del sistema económico, y del que inexorablemente se derivan los imponderables que justifican determinadas medidas políticas o fundamentan la exigencia de "adaptación" de los agentes sociales al hecho de la globalización como única respuesta a las nuevas condiciones creadas por él. Nos encontramos pues ante un concepto no meramente descriptivo, sino también con derivaciones normativas o ideológicas, en el sentido de exigir y fundamentar determinadas conductas, así como de "naturalizar" procesos sociales y sus consecuencias.

Una de las convicciones difusas, pero de mayores consecuencias en relación con la globalización, es la convicción ciertamente pesimista de que, frente a los mercados globalizados, se ha vuelto imposible toda acción reguladora de tipo financiero o político. En los círculos de las élites económicas, políticas o consultoras con poder de deci- 
sión y dirección se ha extendido una retórica de la globalización que contiene y promociona una visión del mundo según la cual las posibilidades de acción de los actores políticos tienden a volverse insignificante en los sistemas globales. Dicha retórica está claramente al servicio de la autodisculpa de la clase política, que ya sólo puede (o quiere) aspirar, cuando mucho, a servir de "quita-obstáculos" al proceso de globalización.

Los globalistas extremos sacan la conclusión de que, queramos o no, ya no podemos controlar o dirigir las economías nacionales e internacionales hacia objetivos socialmente deseables $y$, porque ya no podemos, carece de sentido que debamos. Economistas de corte neoliberal van incluso más allá y reafirman ese no debemos con el argumento moral de que la libre competencia maximiza idealiter el bienestar de todos. La globalización económica es presentada como el medio para acercar ese ideal a su realización. Contra la evidencia contraria de los hechos se afirma que con unos mercados globales y liberalizados se sirve mejor al bien común general que con una globalización regulada democráticamente y que por ello aquéllos son preferibles moralmente a ésta.

La teoría neoliberal atribuye al mercado una competencia sin igual para solucionar todos los problemas de localización de los factores de producción y de la asignación de ingresos. Su mano invisible se encarga de corregir eficazmente las disfunciones del sistema, en especial los mercados financieros, cuya función orientadora aviva la competencia y estimula la modernización, evita el despilfarro y corrige los desarrollos erróneos. De modo que la eliminación de las barreras que impiden el libre intercambio y la mundialización tanto de la producción como de los flujos financieros son la condición sine qua non del abaratamiento de los costes, de la innovación técnica y de la permanente dinamización de la economía. Lo que resulta incomprensible en el marco de este discurso es que los gobiernos defensores del mismo sean los que emplean medidas más restrictivas al acceso de inmigrantes al mercado de trabajo. Frente a los mercados de capitales, de bienes y servicios, el mercado de trabajo es el menos integrado a nivel internacional. Bien podría decirse que en el cierre de las fronteras a los inmigrantes se ponen de manifiesto las verdaderas intenciones de la globalización neoliberal. 
No se puede negar que hemos asistido en la última década a un crecimiento de la interdependencia mundial. $\mathrm{Ha}$ crecido el volumen del comercio internacional por encima del crecimiento de la producción mundial de bienes. Más rápido que el comercio mundial han crecido las inversiones extranjeras directas a cargo sobre todo de grupos de empresas transnacionales. En relación con estas inversiones, aunque en mayor medida vinculado a transacciones especulativas, se ha producido un rápido crecimiento de los flujos internacionales de capital, que dadas sus dimensiones debilitan o incluso imposibilitan los intentos de políticas monetarias y fiscales nacionales autónomas. A través de inversiones en ramas productivas y en servicios relacionados con ellas intensivos en capital y tecnología han surgido interrelaciones que van más allá de meras traslaciones empresariales en busca de retribuciones bajas del factor trabajo, de modo que se puede hablar de una importante internacionalización de la producción. Suministro, producción, prestación de servicios relacionados con la producción así como el marketing y la venta pueden ser optimizados por las grandes empresas transnacionales a escala global. También ha crecido vertiginosamente el mercado global de bienes "culturales" y de la comunicación así como la oferta de bienes y servicios crecientemente estandarizados a escala mundial, para lo que se ha acuñado términos como "MacDonaldización" o "Disneylandización" de la sociedad. Todos estos fenómenos no habrían sido posibles sin la revolución tecnológica de la microelectrónica, la informática, las telecomunicaciones y la optoelectrónica.

Pero también es cierto que todo este proceso se ha desarrollado bajo el dominio de fuertes asimetrías, la hegemonía de tres regiones económicas principales (EE.UU., UE y Japón), la polarización entre zonas productivas ricas donde se acumulan la información y la riqueza y zonas empobrecidas con economías devaluadas y fuerte exclusión social. Los mercados de bienes y servicios sólo se han liberalizado de modo incompleto y casi siempre de manera desventajosa para los países menos desarrollados. El proteccionismo que se combate siempre es el de los otros más débiles. En realidad se han mantenido y fortalecido las pautas de dominio heredadas históricamente a través de un emplazamiento diferencial en la división internacional del trabajo, que supone de hecho la exclusión de grandes regiones rurales, países enteros del todo el mundo, gran parte de continente africano y

Globolizaclón y migraciones. Una mirada desde Europa solidaria con el Sur 
grandes sectores de población en países y regiones ricas. En cierto modo nos encontramos ante la paradoja de que nuestro mundo se ha vuelto más unitario y más desgarrado a la vez.

Los datos que ofrecen los últimos informes del Programa de las Naciones Unidas para el Desarrollo hablan por sí solos:

\begin{tabular}{|l|c|c|}
\hline Desigualdades del consumo & $\begin{array}{c}20 \% \\
\text { más rico }\end{array}$ & $\begin{array}{c}20 \% \\
\text { más pobre }\end{array}$ \\
\hline Consumo de carne y pescado & $45 \%$ & $5 \%$ \\
Consumo de energía & $58 \%$ & $4 \%$ \\
Líneas telefónicas & $74 \%$ & $1,5 \%$ \\
Consumo de papel & $84 \%$ & $1,1 \%$ \\
Flota mundial de vehículos & $87 \%$ & $1 \%$ \\
Gastos en consumo privado & $86 \%$ & $1,3 \%$ \\
\hline
\end{tabular}

En los últimos 30 años, la participación en el ingreso mundial del $20 \%$ más pobre de la población mundial se redujo de 2,3\% (1960) a $1,4 \%$ (1991) y a $1,1 \%$ (1997). Mientras tanto, la participación del $20 \%$ más rico aumentó de $70 \%$ a $85 \%$. Así se duplicó la relación entre la proporción correspondiente a los más ricos y a los más pobres, de 30:1 (1960) a 61:1 (1991) y a 78:1 (1994). Hay en el mundo 358 personas cuyos activos se estiman en más de mil millones de dólares cada una, con lo cual superan el ingreso anual combinado de países donde vive el $45 \%$ de la población mundial. En los últimos tres decenios, la proporción de gente cuyo ingreso per cápita creció por lo menos a un ritmo de $5 \%$ anual se duplicó con creces, del $12 \%$ al $27 \%$, en tanto que la proporción de los que experimentaron un crecimiento negativo se triplicó ampliamente, de $5 \%$ a $18 \%$. La diferencia en cuanto al ingreso per cápita entre el mundo industrializado y el mundo en desarrollo se triplicó, de 5.700 dólares en 1970 a 15.400 dólares en 1993.

Pero no nos enfrentamos sólo a una pobreza relativa y una desigualdad creciente, sino a una situación alarmante de pobreza absoluta. Alrededor de un tercio de la humanidad, 1.300 millones de personas, viven con un ingreso inferior a 1 dólar diario. Según el Informe del PNUD de 1998, de los 4.400 millones de habitantes del mundo 
en desarrollo, casi tres quintas partes carecen de saneamiento básico. Casi un tercio no tiene acceso a agua limpia. La cuarta parte no tiene vivienda adecuada. Un quinto no tiene acceso a servicios modernos de salud. La quinta parte de los niños no asiste a la escuela hasta el quinto grado. Alrededor de la quinta parte no tiene energía y proteínas suficientes en su dieta. Las insuficiencias de micro-nutrientes son incluso más generalizadas. En todo el mundo hay dos mil millones de personas anémicas, incluidos 55 millones en los países industrializados. Esto supone que anualmente 200 millones de personas se vean afectadas por la tuberculosis y que unos 5 millones de lactantes y niños mueren por infecciones agudas de las vías respiratorias. El $94 \%$ de las personas con sida viven en países subdesarrollados, especialmente en el África subsahariana. 507 millones de personas tienen una esperanza de vida inferior a 40 años, 158 millones de niños menores de 5 años sufren malnutrición y 800 millones de personas no tienen recursos suficientes para comer.

Todas estas cifras, por lo demás suficientemente conocidas, no pretenden ninguna exhaustividad, ni tampoco simplificar en su generalidad la multiplicidad de situaciones que en ellas quedan subsumidas: desigualdad entre zonas rurales y urbanas, entre hombres y mujeres, entre regiones en los mismos países, entre adultos y niños, entre etnias, etc. Quizás por esa razón sería conveniente atender sobre todo a la dinámica del sistema mundial tal como se manifiesta en los procesos de diferenciación social: en el ámbito de las relaciones de distribución y consumo o en la forma de apropiación desigual de la riqueza nos encontramos con una creciente desigualdad, polarización, pobreza y miseria. En las relaciones de producción asistimos a una individualización del trabajo, sobreexplotación de los trabajadores, exclusión social e integración perversa.

Esta forma de globalización neoliberal es inseparable de la primacia del capital financiero y la liberalización casi completa de los movimientos de capital. Las bolsas de los países más ricos desplazan del protagonismo económico a las factorías y las fábricas donde se asienta la producción. Las operaciones de los mercados de capital no sólo han aumentado desproporcionadamente en las últimas décadas, sino que representan ya un volumen sesenta veces superior al volumen de intercambios de bienes y servicios. Asistimos a una constante innovación en el campo de los productos financieros que favorece sobre 
todo la tendencia especulativa de los mercados de capital. Ya no es la actividad empresarial la que encuentra reflejo en dichos mercados, sino las operaciones de fusión, de compra-venta de empresas, las inversiones de duración sumamente breve en determinados países con altas tasas de interés, etc. La lógica que preside todas estas operaciones es la de obtener el máximo rendimiento en el período más corto de tiempo. La economía del papel ya no está al servicio de la economía real. De modo que los representantes de los fondos de inversión no dudan en aplicar estrategias de desinversión masiva en determinados países con consecuencias catastróficas para sus poblaciones o premiar fusiones o compra-ventas de empresas asociadas con despidos masivos, si de ello se derivan mayores beneficios a corto plazo para sus representados accionistas, que son quienes les pagan. Esta dinámica resulta especialmente relevante, si tenemos en cuenta el carácter determinante de los capitales errantes en la presión sistémica al crecimiento y a la sobreexplotación de las reservas naturales, así como en los procesos inflacionarios y en el crecimiento de las diferencias entre los ricos y los empobrecidos a escala mundial.

A pesar de la retórica de la liberalización del comercio, el Sur sigue sufriendo el fuerte proteccionismo a sus productos manufacturados y agrícolas en los países del Norte. Los precios de la materias primas han descendido al nivel de hace cincuenta años, mientras los bienes que importan los países del Sur no han deja de subir. Aunque la Organización Mundial del Comercio tiene como objetivo promover la convergencia de los niveles de desarrollo y de vida entre todos los países del planeta, para ello defiende como único camino viable la fórmula neoliberal de "eliminar obstáculos para el comercio entre la naciones". Pero la liberalización se hace al dictado de las grandes corporaciones y sin consideración del impacto social o medioambiental de las políticas comerciales. Qué se considera "barrera comercial" y qué no, depende de las posiciones de poder de los Estados y de las corporaciones transnacionales. Los países empobrecidos se ven sometidos de nuevo a la ley del embudo encubierta bajo una retórica de liberalización. La propia OCDE y el Banco Mundial reconocen que de las ganancias derivas de la aplicación de los acuerdos de la Ronda de Uruguay el $64 \%$ recayó sobre los países del Norte.

La primacía del capital financiero y de la liberalización asimétrica del comercio internacional ha tenido como resultado una concentra- 
ción asombrosa del poder económico. En todos los sectores económicos estratégicos, en las telecomunicaciones, la industria aero-espacial, el ámbito energético, la industria farmacéutica, la banca, los medios de comunicación, la siderurgia y el automóvil, etc. los mercados han adquirido un carácter oligopolístico. De modo asombroso asistimos a una destrucción de competitividad por los que se declaran sus más firmes defensores. La cuota del capital transnacional en relación con el Producto Interior Bruto mundial no ha dejado de crecer en las últimas décadas, pasando del $17 \%$ en la primera mitad de los años setenta al $31 \%$ en 1995 . De modo que las transnacionales han adquirido tal poder frente a los gobiernos de los países empobrecidos, que éstos se ven privados de toda posibilidad negociadora frente a aquellas. No pueden más que ofrecer las mejores condiciones posibles para sus inversiones (facilidades para exportar los beneficios, subvenciones, infraestructuras, exenciones fiscales, etc.), aunque sea incluso a costa de los derechos de los trabajadores y de su participación en los beneficios obtenidos por las empresas. Asistimos de este modo a una carrera internacional por la disminución de los costes laborales que perjudica de modo especial a los estratos más bajos del mercado de trabajo de los países desarrollados y a amplias capas de trabajadores de los países en desarrollo.

\section{Factores de la globalización que más pueden influir sobre las migraciones}

Los factores que ahora analizaremos no explican desde un punto de vista causa-efecto los flujos migratorios. Miles de millones de personas se ven sometidos a ellos y tan sólo una pequeñísima parte toma la decisión de emigrar. Las cifras que baraja la ONU no llegan a los 150 mill. las personas que viven fuera de su país de origen, de los que aproximadamente sólo el $16 \%$ se encuentra en Europa. En realidad, una vez que veamos el panorama mundial y la situación en la que viven las mayorías empobrecidas del Sur, lo que necesitará explicación no serán tanto los flujos migratorios, cuanto el hecho de que sean tan pocos lo que dan el paso de emigrar. Sin embargo, analizar dichos factores permitirá trazar el marco que hace comprensibles las migraciones.

Como se ha señalado más arriba, en la década de los setenta se produce una coincidencia entre una rápida afluencia de capitales des- 
de los países productores de petróleo (petrodólares) y un descenso de la demanda de fondos en los países más industrializados. En los países del Sur tenía lugar en ese momento una fase de expansión económica. De modo que los excedentes de capital fueron canalizados hacia esos países. Mientras que los intereses que se establecieron al principio eran relativamente bajos, en los años ochenta cambiaron las condiciones para las renegociaciones de la deuda y para los nuevos créditos necesarios para pagar la misma. De este modo se produjo un efecto de bola de nieve de la deuda externa. Cuanto más se pagaba, más se debía. En 1997 la deuda se había multiplicado por 16 respecto al año 1970, alcanzando la cifra de 1,95 billones de dólares.

El pago de la deuda se ha vuelto imposible. Pero más allá de su valor real en términos de capital, la deuda se ha convertido en una palanca poderosísima con la que el Norte impone unas condiciones totalmente desventajosas para el Sur en el comercio internacional, se mantiene el saqueo de las materias primas, que pierden constantemente valor en los mercados internacionales, y se obliga a los países endeudados a abrir sus economías a la intervención del capital y las empresas transnacionales en las condiciones más ventajosas para ellas.

El Fondo Monetario Internacional se ha convertido en el principal mediador entre los gobiernos de países endeudados y los bancos acreedores. La concesión de nuevos créditos ha venido siendo condicionada a la aplicación de los planes de ajuste estructural, cuyos elementos fundamentales son el recorte del gasto público, la devaluación de la moneda, la privatización de las empresas públicas, etc. El FMI se ha dedicado ha exigir con toda firmeza de los países del Sur disciplina monetaria y austeridad. Con el fin de que paguen la deuda se ha promovido en muchos casos la "dolarización" de sus economías.

Los resultados de esta política económica sobre las poblaciones del Sur son bien conocidos. Entre los más llamativos cabe mencionar las crisis periódicas a las que se ven sometidos sus países a causa de la movilidad de los capitales y la dependencia de sus mercados frente a los agentes económicos transnacionales y sus estrategias cambiantes. México en 1994, el Sudeste Asiático en 1997, Rusia en 1998, diferentes países de América Latina entre 1998 y 1999 y, en la actualidad, Argentina, configuran un rosario de crisis que se han hecho sentir de modo dramático en los sectores más pobres y llegan a alcanzar a las clases medias, que se ha visto abocadas a una pobreza frente a la que 
se sentían seguras. La dinámica de las crisis responde a un esquema que se repite. La salida de capitales de dichos países produce una reacción en cadena que lleva a una pérdida de las líneas de crédito hasta ese momento disponibles, a una necesidad de disponer de los bienes adquiridos con dichos créditos, a una desaceleración del crecimiento, a un aumento del paro, a una escasez de crédito y liquidez, a un crecimiento del impago de préstamos y descrédito del sistema bancario. En la crisis de Indonesia, por ejemplo, se calcula que número de pobres aumentó en medio año de 22 a 98 millones.

El deterioro medioambiental es otro factor importante a tener en cuenta. Se puede decir que existe en la actualidad una espiral de retroalimentación negativa entre pobreza y destrucción del medio ambiente, en la que el deterioro del segundo conduce al aumento de la primera y viceversa, la primera se convierte en una dificultad para la regeneración del segundo. Los pobres se ven obligados a agotar los recursos para sobrevivir, pero esta degradación del medio ambiente los empobrece todavía más. Siendo los ricos los que más contaminan, sin embargo son los pobres los que soportan las peores consecuencias.

En la segunda mitad del siglo XX, la agricultura del Tercer Mundo ha sido crecientemente integrada en la división internacional del trabajo por medio de un proceso acelerado de salarización del primer sector y su sometimiento a las estrategias empresariales de los grandes consorcios agroalimentarios. Junto a esto la industrialización orientada a la exportación y dependiente del capital inversor extranjero ha movilizado importantes capas de población hacia los núcleos urbanos y el trabajo asalariado. La primera consecuencia es el éxodo a las ciudades que se produce en los países del Tercer Mundo. Se calcula que anualmente emigran entre 20 y 30 mill. de personas del campo a las ciudades. En el 2025 el $57 \%$ de la población de estos países vivirá en las ciudades.

De esta manera el proceso globalizador crea potenciales migratorios y refuerza los lazos ideológicos, culturales y materiales entre el centro y la periferia, entre los países de los que procede el capital y los países de procedencia de los inmigrantes. Como se ha señalado más arriba, el mercado mundial dominado por los países de la OCDE ha sido hasta ahora la palanca más poderosa del saqueo de la naturaleza en los países del Tercer Mundo a través de la demanda de materias 
primas minerales y de alimentos tropicales (monocultivos), exportación de pesticidas, demanda de maderas nobles, políticas financieras que han generado una deuda económica que deja sin opción a los países pobres abocados a una explotación despiadada de sus propios recursos naturales irremplazables, etc.

Durante el proceso de descolonización de bastantes países del Tercer Mundo después de la segunda Guerra Mundial y durante el período de la llamada guerra fría muchos de ellos se vieron involucrados en conflictos bélicos que generaron desplazamientos masivos, de los que sólo una parte muy reducida afectó a los países desarrollados. El final de guerra fría no ha supuesto el fin de esos conflictos, en la era de la globalización más bien han aumentado si cabe sus efectos sobre las poblaciones civiles. El Alto Comisionado de Naciones Unidas para los Refugiados (ACNUR) calcula que 50 mill. de personas en el mundo son víctimas de desplazamientos forzosos, 21 mill. de los cuales están bajo su responsabilidad. Pero la mayoría de los refugiados del mundo se encuentran en los países vecinos, ellos también empobrecidos. Aunque en otros países europeos la afluencia de refugiados ha tenido un cierta relevancia, la reforma legislativa de 1994 ha hecho de España un país prácticamente cerrado para los solicitantes de asilo.

El turismo, los medios de comunicación de masas, sobre todo la televisión, la venta a escala planetaria de productos culturales o de consumo, con sus campañas promocionales, etc., han contribuido muy decisivamente a multiplicar los contactos y las interacciones culturales a escala mundial. Para amplias capas de población de los países empobrecidos el contacto con esos productos culturales se produce frecuentemente en conexión directa con la sustitución o disolución de los marcos tradicionales de vida y sus modelos de comportamiento. Así que no parece aventurado afirmar que el proceso de expansión cultural de occidente tiene un efecto directo sobre la predisposición a emigrar, al favorecer el desarraigo y al universalizar patrones de consumo y estilos de vida y crear expectativas difícilmente realizables en los países empobrecidos.

El Informe del PNUD de 1998 llamaba la atención sobre el hecho de que es más probable que muchas aldeas del Tercer Mundo estén vinculadas al cine de Hollywood y a la publicidad por la televisión de satélite que por carretera o ferrocarril a otra aldea no demasiado lejana. La cultura del consumismo global impacta de modo masivo sobre 
poblaciones excluidas del mismo y genera una falsa imagen de "El Dorado" en los países ricos sumamente atractiva para los que carecen de la más mínima esperanza de alcanzar unos niveles aceptables de consumo en sus países. Si a esto unimos el crecimiento y abaratamiento de los medios de transporte internacional a que ha llevado la industria del turismo, podremos comprender fácilmente el peso de la industria cultural sobre la determinación a emigrar.

Tampoco debería olvidarse la importancia de las redes migratorias. Las redes sociales juegan un papel primordial en el intercambio de información sobre el país de destino, en los trámites y apoyos para el traslado a él y para la posterior integración en el mercado laboral formal o informal. Los expertos parecen estar de acuerdo que dichas redes se convierten con el paso del tiempo en factor de autoperpetuación de las migraciones más allá de la persistencia de los factores de naturaleza económica que las desencadenaron o de los cambios negativos en el mercado de trabajo o en las políticas migratorias del país de destino.

Asistimos al surgimiento en los últimos tiempos de espacios e identidades transnacionales. Asociadas al proceso de globalización nos encontramos con nuevas formas de concebir y vivir la ciudadanía, nuevas identidades y nuevas concepciones del espacio que cuestionan las divisiones tradicionales de carácter nacional. El concepto de "transmigrante" quiere reflejar la realidad de personas que pertenecen a unidades familiares localizadas en dos o más estados, que mantienen relaciones sociales y económicas y se encuentran insertos en comunidades tanto en su lugar de origen, como en el de destino, que están enraizados en más de una cultura y que viven su doble o triple pertenencia como una nueva forma de ciudadanía.

El espacio transnacional se constituye en el marco de la globalización y depende de la alta movilidad de capital, mercancías, informaciones y servicios asociada a ella. Está relacionado con un cambio de modelo en las migraciones observable en espacios interestatales con una larga experiencia de flujos migratorios. Las migraciones múltiples y pluridireccionales sustituyen a la migración clásica: se trata de personas que van y vienen de un país a otro, en muchos casos sin papeles, y que mantienen contactos y relaciones a ambos lados de la frontera. La redes migratorias establecidas en estos 
espacios permiten una disolución o al menos un debilitamiento de las pertenencias y atribuciones exclusivamente nacionales. Vinculan y transportan personas, bienes, valores, símbolos e informaciones entre diferentes espacios y estados y conforman la identidad de los que se integran en ellas de manera diferente a como lo hacen los referentes exclusivamente nacionales.

Por otra parte, es necesario atender a algunos cambios que se han producido en los países receptores en el horizonte de la globalización neoliberal y que son de gran importancia para comprender la demanda de mano de obra inmigrante. En las economías de los países más ricos existe una tendencia a la segmentación de la fuerza de trabajo con múltiples manifestaciones: el desempleo, la subproletarización de una parte de la mano de obra con una relación sólo esporádica con el mercado de trabajo, la precarización de una parte importante del empleo debida a la flexibilización y el crecimiento de la temporalidad, la dualización y polarización del escalafón profesional, etc. Otro de los aspectos importantes en relación con la inmigración es la economía sumergida. Existen ramas económicas como la agricultura, la hosteleríarestauración y los servicios menos cualificados (limpieza, servicio doméstico, etc.), en los que la incidencia de la economía sumergida es muy elevada. España es uno de los países de la Unión Europea con más economía oculta. Dada esta situación del mercado de trabajo, la inserción laboral de la mayoría de los inmigrantes se viene produciendo en las ramas económicas con más incidencia de la economía oculta y en los segmentos de empleo más precarios y descualificados, con mayor grado de irregularidad y más desprotegidos jurídica, social y sindicalmente. Así pues, la mayor demanda de fuerza de trabajo para puestos peor pagados, inestables y con menos prestaciones sociales es lo que produce la demanda de inmigrantes.

Aunque no tenga una relación directa con la globalización, es necesario que consideremos otro factor de gran importancia: el demográfico. El ritmo de crecimiento de la población mundial en los últimos años es de una media de 84 millones de personas. El 90\% del crecimiento demográfico se produce en el Tercer Mundo. Sin embargo, las sociedades desarrolladas envejecen y pierden población. Si dejamos fuera de consideración la emigración, según fuentes de la ONU, hacia el año 2050 habrá descendido la población en la Unión Europea en 61,6 millones España contará con 30,2 millones de habitantes, 9,4 millones menos 
que en la actualidad. Está evolución llevará aparejada una serie de graves problemas: desequilibrio de flujos en el mercado de trabajo, crisis del sistema de pensiones, sobrecarga del sistema de salud y seguridad social, etc.

Por otro lado, muchos de los países de los que proceden los inmigrantes se encuentran en plena transición demográfica, es decir, disminuye la mortalidad infantil y aumenta la esperanza de vida, pero no disminuye al mismo ritmo el número de nacimientos. Este crecimiento demográfico en países con economías que ya tienen dificultades para asegurar la reproducción de la vida de la población lleva aparejado un importante desplazamiento del campo a las ciudades, hacinamiento urbano, paro, conflictos sociales, etc. Es evidente que la migración puede aliviar la presión en el sur y mitigar la falta de población en el norte. De hecho, la División de Población de la ONU calcula que para mantener hacia el 2025 la misma ratio de activos/ jubilados que existe hoy en Unión Europea ésta debería recibir en torno a 135 mill. de inmigrantes.

\section{Los itinerarios migratorios: el ejemplo de España}

Dado el paso, la migración conlleva para los emigrantes un cambio del sistema social y cultural de referencia en el lugar de origen por el del lugar de destino. Este cambio no se produce de modo automático con el traslado físico de lugar, sino que supone un largo y difícil proceso que a veces perdura a lo largo de toda la vida y llega a afectar a más de una generación ya instalada en país de destino. La caracterización del emigrante como un desarraigado expresa la inestabilidad y vulnerabilidad que produce la migración, la ruptura con la sociedad de procedencia y la introducción en un nuevo contexto social y cultural que conlleva una pérdida de validez de muchas concepciones valorativas, normas de conducta y modelos de comportamiento hasta ese momento asumidos con cierta naturalidad. No es extraño que los inmigrantes, sobre todo en la fase inicial de su estancia en el nuevo país, se sientan desorientados.

La primera gran dificultad viene dada por el muro legal y policial levantado contra ellos. Miremos el caso español. Aunque se sigue manteniendo la ficción legal de que para entrar en el país se necesita permisos de trabajo y de residencia, de hecho el $83 \%$ de los inmigrantes que llegaron a españa en los últimos años entraron sin permiso de 
trabajo. Aunque la imagen popularizada por los medios de comunicación de inmigrantes llegando en pateras a nuestras costas, si bien presenta el drama de muchos seres humanos que arriesgan su vida y llegan a perderla a causa de una política de fronteras inhumana, no refleja más que una mínima parte de los que llegan hasta nosotros $(2 \%)$. El $62 \%$ lo hicieron en avión, como la mayoría de los 50 mill. de turistas que nos visitan al año.

El proceso administrativo que los inmigrantes han de realizar para regularizar su situación una vez en España bien puede calificarse de kafkiano: 1) Obtener una oferta de trabajo. 2) Solicitar de permiso en la Delegación del Gobierno. 3) Enviar una copia de la documentación al país de origen para que un representante del solicitante la entregue en el Consulado Español. 4) El consulado solicita información sobre el solicitante a Madrid. 5) De Madrid se solicita información a la Delegación del Gobierno. 6) La Delegación desempolva el expediente y solicita información a la institución competente sobre la "situación nacional de empleo" y toma una decisión afirmativa o negativa. 7) Recorrido de vuelta de la documentación vía Madrid al Consulado correspondiente. 9) El Consulado revisa la documentación y concede el visado. 10) El extranjero debe viajar al país de origen a recogerlo. 11) Lo presentará en la Delegación del Gobierno para que se lo sellen y le concedan la tarjeta de residencia. Sin contar las arbitrariedades que este proceso en su ejecución permite, la lentitud de su tramitación -entre 12 y 15 meses en promedio- contradice los principios jurídicos más elementales, que por cierto están recogidos en la Ley de Procedimiento Administrativo y que simplemente no se aplican a los inmigrantes.

Las dificultades de acceso suponen para la mayoría una fase de irregularidad con efectos perversos tanto desde el punto de vista de seguridad personal, como de integración laboral, social, etc. Si se llega a obtener una primera regularización, la vinculación entre permiso de trabajo y de residencia, así como el tipo de vigencia temporal de ambos, por un lado, y la política de cupos, que orienta la fuerza de trabajo inmigrante hacia ocupaciones específicas con un índice mayor de irregularidad y precariedad, por otro, los atrapa por un período prolongado de tiempo en un círculo vicioso de inestabilidad laboral y jurídica, que aumenta considerablemente la vulnerabilidad y la discriminación de los inmigrantes en el mercado de trabajo. Todo parece establecido para responder a la demanda de mano de obra en los sec- 
tores del mercado de trabajo no deseados por los autóctonos, es decir, aquellos con una alta tasa de economía sumergida, bajo reconocimiento social, escasa movilidad en la escala social, baja remuneración, alta temporalidad, fluctuaciones de la demanda y, frecuentemente, condiciones de sobreexplotación.

Para aquellos que a pesar de estos escollos consiguen instalarse entre nosotros, gran parte de los aprendizajes realizados en el contexto de origen pierden en el nuevo contexto su validez. Los emigrantes han de distanciarse de un buen número de roles y redefinir aquellos que se mantienen para responder a las expectativas con las que están vinculados en la sociedad receptora. Otros roles han de ser asumidos de manera completamente nueva. Una reacción frecuente a esta situación y los retos que comporta es la reducción de las interacciones sociales, limitar la vida relacional a la familia, el grupo de compatriotas o a los parientes. La inseguridad existencial y los problemas de orientación agudizados por la habitual experiencia de rechazo en el nuevo contexto lleva frecuentemente a la segregación y guetización.

Convendría, además, no olvidar que los inmigrantes siguen manteniendo vínculos con sus contextos de origen, envían remesas, tienen un doble punto de referencia con lazos específicos y exigencias particulares. Una parte de la familia queda en el propio país, pero la segunda generación se vincula y echa raíces en el nuevo. La integración de los hijos plantea por regla general problemas primero educativos, después de integración cultural, laboral, política, etc. que desbordan las capacidades de respuesta de los inmigrantes. Los países receptores, España incluida, no han sabido o querido articular políticas efectivas de integración, porque se ha actuado desde las administraciones públicas primando los criterios económico-laborales, de seguridad, de soberanía nacional, etc.

\section{Barreras que deben eliminarse}

Hay que empezar refiriéndose al marco legal que define el estatuto jurídico y determina las condiciones de existencia de los inmigrantes. Todas las leyes de extranjería tienen un carácter no sólo diferenciador, sino también discriminador, ya que establecen un régimen jurídico específico para los no nacionales y les recortan el ejercicio de derechos fundamentales, que sí están reconocidos a los detentadores de la nacionalidad. 
Desde mediados de los años 70 asistimos a un fortalecimiento de las restricciones contra la inmigración en casi todos los países receptores de la misma. El proceso de unificación europea, por ejemplo, ha supuesto una liberalización de los movimientos y las posibilidades de establecer residencia para los ciudadanos de los países miembro, pero un endurecimiento de los controles y dificultades para los inmigrantes procedentes de fuera de la Unión, exceptuado el grupo de las personas altamente cualificadas o ricas. Dicho endurecimiento ha seguido un patrón jurídico dominado por la tendencia a favorecer la discrecionalidad de la administración en el tratamiento de las solicitudes de entrada o permanencia de los extranjeros, sobre todo de los llamados inmigrantes económicos, y la priorización de los supuestos intereses del país receptor frente a las necesidades o pretensiones de los solicitantes. La creación de lo que ya se conoce como la fortaleza europea parece destinada a salvaguardar el espacio de prosperidad económica y garantías políticas y sociales de la UE frente al mundo exterior percibido como amenaza de las mismas. Resulta paradigmático que, desde el Acuerdo de Schengen, el tratamiento administrativo de la inmigración a nivel europeo se venga asociando a fenómenos como el terrorismo, la delincuencia organizada, el tráfico de drogas, etc.

Pero aunque parezca paradójico, el muro y los agujeros se reclaman mutuamente en la configuración de las fronteras, verdaderos filtros selectivos, que sirven para mantener las afluencias y, al mismo tiempo, las diferencias institucionalizadas en la retribución directa o indirecta del trabajo. Lo que convierte a las migraciones en un subsistema laboral es esa combinación entre integración precaria en el mercado de trabajo y exclusión parcial o total de los derechos ciudadanos y sociales. Además de la discriminación que supone una asignación de los inmigrantes por vía de ley a sectores y actividades con un índice mayor de irregularidad y precariedad, la posición que ocupan los inmigrantes laborales dentro de los respectivos mercados de trabajo, en gran medida condicionada por el tipo de acceso a los mismos, es peor de modo sistemático. La falta de contrato va acompañada en muchos casos de discriminación salarial, de condiciones de trabajo con riesgos para la salud, de jornadas de trabajo abusivas, etc. Asistimos a una nueva forma de esclavitud y de reducción de seres humanos a mano de obra barata y explotable supeditada a las exigencias arbitrarias de los contratantes. 
Además de la discriminación que supone una asignación de los inmigrantes a sectores y actividades con un índice mayor de irregularidad y precariedad, la posición que ocupan los inmigrantes laborales dentro de los respectivos mercados de trabajo, en gran medida condicionada por el tipo de acceso a los mismos, es peor de modo sistemático. La media de los trabajadores extracomunitarios se encuentra en peores condiciones que los españoles. En el caso de la agricultura, esto supone una inserción casi exclusiva en la modalidad eventual de trabajo y unas enormes dificultades para la inserción social debidas a la estacionalidad (cambio frecuente de zonas de trabajo, alojamiento en infraviviendas, imposibilidad de reunificación familiar, etc.). En el caso del servicio doméstico, las inmigrantes son empleadas en muy buena parte como "internas", lo que conlleva frecuentemente condiciones de explotación extrema, tanto por los horarios de trabajo, el grado de informalización y los salarios inferiores, como por la dependencia casi total respecto de las familias que las contratan. En la construcción se observa un predominio de la ocupación de los inmigrantes en la categoría de peón no cualificado. Sufren en mucha mayor proporción que los autóctonos la privación de derechos laborales como pagas extra, vacaciones pagadas, etc. De modo general para todos los sectores y actividades puede decirse que los inmigrantes se ven afectados en mucha mayor proporción que los autóctonos por la informalidad.

La discriminación legal y laboral están a la base de otras formas de discriminación que afectan a desarrollo normal de la existencia y a los niveles mínimos de calidad de vida vigentes en la sociedad receptora de inmigración. Nos referiremos aquí sólo a una de esas formas por su gran relevancia de cara a la integración social de los inmigrantes, la que está relacionada con la vivienda. Aun a riesgo de simplificaciones reductoras, se puede decir que en las ciudades los inmigrantes suelen ocupar viviendas muy deterioradas, con escasos equipamientos, en las zonas de mayor pobreza de los centros urbanos degradados o de los barrios periféricos. Se trata muchas veces de viviendas para las que no es posible encontrar inquilinos en el mercado del alquiler "normal", pero que gracias a las dificultades adicionales que tienen los inmigrantes para encontrar vivienda, se convierten en una fuente de ingresos muy rentable para sus propietarios, que se suelen considerar eximidos de las obligaciones de conservación y reparación. 
El hacinamiento es una estrategia tanto de los inmigrantes para distribuir el coste entre más, como de los propietarios para poder cobrar más y, llegado el momento, justificar la expulsión. En las zonas rurales los inmigrantes se alojan predominantemente en naves, casas abandonadas, dependencias secundarias de los cortijos, pequeños barrios en medio del campo, etc. que suelen pertenecer a los mismos patronos que los contratan. El alquiler es a veces de tipo personal, es decir, se cobra a cada uno de los inquilinos una cantidad, con lo que el hacinamiento supone un crecimiento de los ingresos. Los equipamientos son escasos o inexistentes. La proximidad a los lugares de producción agrícola que caracteriza estos alojamientos está emparejada con la lejanía de los núcleos de población, lo que se convierte en una fuente de segregación. La primera contribuye a la disponibilidad de los inmigrantes como reserva de mano de obra, la segunda a la invisibilización de sus necesidades y derechos.

Si los condicionantes político-legales y socioeconómicos juegan un papel determinante en las dinámicas de discriminación de los inmigrantes, no podemos olvidar tampoco las actitudes y comportamientos de la población nativa en la sociedad receptora, es decir, el rechazo xenófobo como obstáculo a la integración y como fundamento difuso o refuerzo cultural de los mencionados condicionantes discriminadores.

Lo característico de la discriminación étnica es la combinación de "diferenciación" e "interiorización". La discriminación racial es aquella a la que se somete a un grupo sobre la base de una construcción social de rasgos diferenciadores considerados como si se tratara de diferencias raciales. Se produce así una vinculación entre características fenotípicas y/o culturales del grupo y discriminación o segregación social. La conducta discriminatoria se sustenta en actitudes de rechazo apoyadas en estereotipos deformados sobre el otro justificados con ideologías racistas. Aunque en un sentido genérico no existe ninguna captación de la realidad libre de prejuicios, cuando se habla de prejuicios en nuestro contexto se está designando aquellos juicios de carácter negativo, que suelen englobar a todo el grupo de individuos sobre los que se emiten, que tienen un carácter previo a la experiencia, cuando no una absoluta falta de relación con la misma, y que se resisten a la refutación por los hechos. El vínculo del prejuicio con la discriminación proviene de su entrelazamiento con intereses de do- 
minación o segregación de los individuos sobre el que se proyecta o con la necesidad de encontrar una explicación causal sencilla o un chivo expiatorio para problemas sociales complejos. No es infrecuente la naturalización de aspectos del comportamiento de los individuos objeto de discriminación, al margen de toda consideración social, económica o histórica sobre la génesis de esos aspectos, en gran medida fruto del mismo proceso discriminatorio. Es una manera de estigmatizar al grupo y preparar su dominación o su exclusión. La etnicidad se convierte así en un excelente instrumento para mantener la sobreexplotación sin excesivos conflictos.

Los estereotipos más frecuentemente asociados con los inmigrantes son la pobreza, la delincuencia, la ausencia de higiene, el hipermachismo y la violencia sobre la mujer, el "atraso" cultural, el integrismo religioso, etc. A las mujeres negras o mulatas se las asocia muy a menudo con la prostitución y con un comportamiento sexual desinhibido. A las personas latinoamericanas se les vincula con el tráfico de drogas, etc. Como hemos visto más arriba, a estos rasgos atribuidos a los colectivos de inmigrantes se le da un carácter casi natural o congénito, lo que fija de modo inamovible el perfil social y cultural de los mismos en el nivel más bajo de la estratificación social e hace impensable toda intervención social contra la discriminación o la segregación. La leyenda de la discriminación positiva frente a los nacionales por parte del Estado o de las instituciones sociales, lo que no es más que un sarcasmo a la luz de la situación que sufren los inmigrantes, resulta ser el mejor antídoto contra los esfuerzos de integración y un potente refuerzo de las discriminaciones existentes.

Los discursos que legitiman el rechazo xenófobo son de diversa índole y se mueven por lógicas distintas. Señalemos dos de estas lógicas de identificación/diferenciación en relación con los extranjeros que subyacen a las actitudes y comportamientos discriminatorios en relación a ellos. Una sería la naturalización del Estado-nación. Bajo esta lógica, las migraciones aparecen de modo general como una excepción anormal, por lo que queda justificada la subordinación, postergación o supeditación de los derechos legales, económicos o sociales de los inmigrantes respecto a los de los nacionales. El Estado tiene unas obligaciones frente a la población autóctona que no son extendibles al resto de personas que viven en el territorio nacional o al menos en la misma profundidad o amplitud. Otra lógica sería la de la 
diferencia cultural, bajo la que las culturas aparecen como realidades cerradas e incomunicables y representan diferentes grados de evolución que las hace superiores o inferiores. Esta lógica puede adoptar la forma de fundamentalismo cultural o de racismo diferencialista, pero en cualquier caso a los culturalmente distintos no les queda otra opción que la de asimilarse a la cultura de la sociedad receptora o, si esto no es posible, vivir segregados de modo que quede neutralizada la supuesta "amenaza" que representan para la "normalidad" dominante.

\section{Compromiso solidario con los inmigrantes}

Igual que con respecto a otros fenómenos complejos, no sirve de nada pretender dar recetas sencillas para la inmigración. En realidad, lo primero sería tomar conciencia de que la inmigración no es abordable como si se tratara de un asunto específico aislado del conjunto de la sociedad. Más bien tendríamos que pensar que ella es como un espejo que nos devuelve aumentados los problemas que vivimos en nuestra sociedad, ya se trate de lo que está ocurriendo en el mercado de trabajo, en las relaciones Norte-Sur, en la crisis del Estado del Bienestar, en la concepción de la ciudadanía y la democracia o en la convivencia multicultural y la cohesión social. Algunas líneas de compromiso podrían ser:

1. COMPROMISO POLÍTICO: Comprender que la inmigración no sólo plantea problemas de integración social, sino que es posee una dimensión política, que es necesario trabajar por una igualdad jurídica, para que los inmigrantes tengan los mismos derechos y libertades que el resto de ciudadanos.

2. COMPROMISO SOCIAL: Exigir de las administraciones públicas la eliminación de toda discriminación en el acceso a la vivienda, al trabajo, a los servicios sociales, etc. denunciando todas las situaciones en que se produce la discriminación y organizándose contra ella.

3. COMPROMISO CULTURAL: Combatir en el día a día los estereotipos y prejuicios acerca de los inmigrantes, buscando el contacto real, reconociendo y valorando sus diferencias culturales, afirmando su dignidad y la importancia de una convivencia en plano de igualdad. 